(M12) was observed yet significant improvement in disease activity was found in both groups. Hence,results from the 2 groups were combined to ascertain if achieving sustained DAS remission can prevent AS progression. The disease activity improved significantly [DAS: $4.8(4.2,5.6)$ at baseline (BL) vs $2.38(1.6,3.0)$ at M12, $p<0.001]$. $57 \%$ patients achieved DAS remission at M12 and $36 \%$ patients achieved DAS remission over 3 consecutive visits (sustained remission). No significant differences were found in disease activity, cardiovascular risk factors (CRF) and baPWV at BL between groups who can (CA) or cannot achieve (NA) sustained remission. At M12, no significant differences in CRF and baPWV were found between groups. However, the change in baPWV was significantly different between CA and NA group $[-65.5(-147.25,44.0) \mathrm{cm} / \mathrm{s}$ vs $39(-65.25,124.75) \mathrm{cm} / \mathrm{s}, p=0.005]$. The differences remained significant in the \%change of baPWV $[-4.4(-9.67-2.84) \%$ vs $2.51(-4.34-10.28) \%, p=0.006] .1$ $\mathrm{n}$ univariate analysis,assocation of change in baPWV and potential predictors included BL baPWV, blood pressure (systolic \& diastolic) and sustained DAS remission was found.By multivariate analysis, achieving sustained DAS remission was an independent predictor for baPWV reduction.

Table 1- Changes in baPWV over a period of 12 months in patients who can or cannot achieve sustained DAS remission in 3 consecutive visits

\begin{tabular}{|c|c|c|c|c|}
\hline & \multicolumn{3}{|c|}{ Sustained DAS remission in 3 consecutive visits } & \multirow[b]{2}{*}{$p^{*}$} \\
\hline & No $(n=64)$ & Yes $(n=36)$ & $p$ & \\
\hline \multicolumn{5}{|l|}{ Baseline characteristics } \\
\hline Female $(n, \%)$ & $47(73.4 \%)$ & $30(83.3 \%)$ & 0.259 & \\
\hline Age (year) & $51.6 \pm 12.8$ & $54.9 \pm 13.2$ & 0.232 & \\
\hline DAS 28 & $5.01 \pm 1.04$ & $4.81 \pm 0.92$ & 0.327 & \\
\hline SDAI & $27.4(20.02,41.08)$ & $26.55(18.95,33.5)$ & 0.343 & \\
\hline Diabetes $(n, \%)$ & $5(7.8 \%)$ & $3(8.3 \%)$ & 0.927 & \\
\hline \multicolumn{5}{|l|}{ Mean baPWV (cm/s) } \\
\hline Baseline & $1422.5(1207.5,1581)$ & $1478.5(1286.3,1624)$ & 0.166 & \\
\hline Month 12 & $1436(1264,1636.3)$ & $1394.3(1244.5,1567.3)$ & 0.698 & \\
\hline Changes in PWV $(\mathrm{cm} / \mathrm{s})$ & $39(-65.25,124.75)$ & $-65.5(-147.25,44)$ & 0.005 & 0.02 \\
\hline Percentage change in PWV, \% & $2.51(-4.34,10.28)$ & $-4.4(-9.67,2.84)$ & 0.006 & 0.012 \\
\hline
\end{tabular}

Conclusions: Effective suppression of inflammation by achieving sustained DAS remission may prevent progression of AS in ERA patients.

Disclosure of Interest: None declared

DOI: 10.1136/annrheumdis-2017-eular.3367

\section{SAT0748-HPR WORKING WITH A MUSCULOSKELETAL DISORDER - A QUALITATIVE STUDY OF WORKERS' EXPERIENCES}

A. Cochrane $^{1}$, C.J. Rothwell ${ }^{1}$, O. FitzGerald ${ }^{2}$, P. Gallagher ${ }^{3}$, J. Ashton ${ }^{4}$, R. Breen ${ }^{5}$, A. Brennan ${ }^{6}$ O. Corcoran ${ }^{7}$, D. Desmond ${ }^{1}{ }^{1}$ Department of Psychology, Maynooth University, Maynooth; ${ }^{2}$ School of Medicine and Medical Sciences, University College Dublin; ${ }^{3}$ School of Nursing and Human Sciences, Dublin City University; ${ }^{4}$ Physiotherapy Services, Beaumont Hospital; ${ }^{5}$ Royal College of Physicians in Ireland; ${ }^{6}$ Physiotherapy Services, AMNCH, Dublin; ${ }^{7}$ Rheumatology Services, Waterford University Hospital, Waterford, Ireland

Background: Musculoskeletal disorders (MSDs) are the leading cause of temporary and permanent work related disability across Europe, yet many people are able to remain at work.

Objectives: To explore perceived facilitators and barriers to staying at work amongst people experiencing MSD.

Methods: Semi-structured interviews conducted with 19 individuals who had attended musculoskeletal assessment clinics in three Irish hospitals within the preceding year with a confirmed diagnosis of non-inflammatory musculoskeletal disorder. Participants were only included if they had been in paid employment continuously for at least six of the previous 12 months. The interviews were audio-recorded and transcribed. Data were analysed using thematic analysis. Results: Participants ranged in age from 21 to 50 years, most were female $(n=16)$. Fifteen participants were continuing to work, while experiencing pain and some functional limitations. Job control emerged as a key factor in continued work participation, specifically, being able to organise workload and make modifications to work practices enabled participants to maintain an acceptable level of work performance. The value of work, both personal and financial, motivated people to continue to work. While some co-workers and supervisors were considered to be helpful, interviewees were concerned that they could lose their job if they asked for assistance or took time off work. Fatigue had a considerable impact on life outside of work, with interviewees reporting effects on family life and reduced participation in social activities.

Conclusions: While continuing to work was beneficial, negative spillover effects on life outside of work were commonly reported. Workers with MSD may benefit from interventions that focus on coping with pain and fatigue management, as well as those that raise awareness amongst employers.

Acknowledgements: This research is funded by the Health Research Board [RCQPS-2014-2].

Disclosure of Interest: None declared
DOI: 10.1136/annrheumdis-2017-eular.2909

\section{SAT0749-HPR THE RELATIONSHIP BETWEEN SPINAL MOBILITY AND STATIC AND DYNAMIC BALANCE IN PATIENTS WITH ANKYLOSING SPONDYLITIS}

B. Unver, H. Yilmaz, F. Unver. Dokuz Eylul University, School of Physical Therapy and Rehabilitation, Department of Orthopaedic Physiotherapy, Izmir, Turkey

Background: Ankylosing spondylitis (AS) is a major chronic rheumatic disease that predominantly affects axial joints, determining a rigid spine from the occiput to the sacrum. The disease can lead to permanent spinal deformity and postural disorder during the later stages. Changes in axial mobility may lead to impaired postural control, with altered postural control being associated with increased fall risk and lower quality of life. The population with AS has been rarely studied regarding postural control, both dynamic and static.

Objectives: The aim was to investigate the relationship between spinal mobility and static and dynamic balance of patients with mild to moderate AS.

Methods: The study included 137 (74 male and 63 female) patients with a mean age of $51.19 \pm 10.72(20-78)$ years who were diagnosed with AS according to the modified New York criteria. Patients were divided into two groups as tragus to the wall distance (TWD) $<15 \mathrm{~cm}$ (Group I = mild AS, $\mathrm{n}=51$ ) and TWD $\geq 15$ (Group II $=$ moderate $A S, n=84)$. The mean duration of disease in Group I was $17.83 \pm 11.3$ $(1-50)$ years and the mean duration of disease in Group II was 20.78 \pm 9.67 (2 43) years. Spinal mobility measurements [TWD, cervical rotation (CR), modified Schober test (MST), lumbar lateral flexion (LLF), intermalleolar distance (IMM), thoracic expansion (TE) tests] were compared with static and dynamic balance tests in the groups. Static balance was assessed with one-foot standing with eyes open and closed. Dynamic balance was assessed with timed up and go test and Berg balance scale.

Results: A statistically significant difference was found between spinal mobility measurements and Berg balance scale scores between the groups. Spinal mobility values of Group II were worse than Group I $(p<0.05)$. Berg balance scale scores were better in Group I than Group II ( $p=0.028)$. No statistically significant difference was found between the two groups in terms of static balance and timed up and go test $(p>0.05)$. There was a weak and significant correlation between spinal mobility measurements [CR, MST, LLF, IMM, and TE] and static and dynamic balance in the positive direction $(r=0.177-0.284, p<0.05)$. There was no significant correlation between TWD and static and dynamic balance $(p>0.05)$. Conclusions: In patients with AS, as the severity of the disease progresses, spinal mobility and dynamic balance worsen; however, the static balance does not change. These changes in the posture and balance can negatively affect patients' participation levels in daily life and increase their risk of falling. For this reason, we think that detailed evaluation of balance, balance training and fall preventing approaches should be included in the rehabilitation programs for the patients with AS.

\section{References:}

[1] Demontis A, et al. Rheumatol Int. 2016;36(3):333-9.

[2] Çınar E, et al. Eur J Rheumatol. 2016;3(1):5-9.

Disclosure of Interest: None declared

DOI: 10.1136/annrheumdis-2017-eular.2278

\section{SAT0750-HPR "IS THIS REALLY THE WAY WE SHOULD GO?”- PATIENT PERSPECTIVES ON RHEUMATOID ARTHRITIS MANAGEMENT}

C.A. Lemay ${ }^{1}$, K. Mazor ${ }^{2}$, J. Kremer ${ }^{3}$, W.B. Nowell ${ }^{4}$, C. Bingham III ${ }^{5}$, J. Curtis ${ }^{6}$ E. Ruderman ${ }^{7}$, L. Harrold ${ }^{8}$. ${ }^{1}$ Orthopedics, University of Massachusetts Medical School; ${ }^{2}$ Meyers Primary Care Institute, Worcester; ${ }^{3}$ Albany Medical College, Albany; ${ }^{4}$ Global Healthy Living Foundation, Upper Nyack; ${ }^{5}$ Johns Hopkins University, Baltimore; ${ }^{6}$ The University of Alabama at Birmingham, Birmingham; ${ }^{7}$ Northwestern University Feinberg School of Medicine, Chicago; ${ }^{8}$ University of Massachusetts Medical School, Worcester, United States

Background: Current rheumatoid arthritis (RA) treatment guidelines suggest aggressive management in order to minimize disease activity. To achieve this goal, clinicians will need to engage patients in shared decision making. Currently little is known regarding patient's preferences and goals for treatment.

Objectives: To understand patient perspectives on their goals with regard to RA disease and flare management and the barriers to, and facilitators of achieving those goals.

Methods: Participants were interviewed utilizing open-ended questions focused on understanding their goals of managing their disease (both disease flares and longstanding disease) as well as the barriers and facilitators of achieving those goals. We explored the following: disease impact; disease beliefs and behaviors; medication use; provider relationship and communication; availability of insurance coverage; and community resources. Interviews were recorded and transcribed. Data were categorized using content analysis techniques. Convenience sample of persons living with rheumatologist-diagnosed RA was recruited from rheumatology practices in 4 states to participate in telephone interviews.

Results: Twenty-seven participants completed an interview from March-August 2015. Mean age was 63 years; $82 \%$ were female and $82 \%$ Non-Hispanic White. Participants reported living with RA for an average of 12 years and $44 \%$ reported 
that their RA was not well controlled. The most common participant goal was to improve or maintain physical function. Barriers to RA and flare management included: 1) Patient Level- lack of knowledge of how to manage flares and a reluctance to change or use medications, related to concerns about potential side effects, and limited understanding of the potential benefits; 2) Provider Levelinadequate communication between patient and provider, specifically in relation to flare management and; 3 ) Health System Level- difficulty navigating insurance, handling coverage gaps, affording high medication costs. Facilitators of RA and Flare management included: 1) Patient Level- successful use of non-medication approaches to disease management and the willingness to initiate conversation with their provider about changing medications and; 2) Provider Level- a positive relationship with their provider, including having trust in the provider, easy access to the provider, and positive communication.

Conclusions: We identified patient-, provider and health system-barriers and facilitators experienced by RA patients achieving their treatment goals. A common theme that emerged was inadequate shared decision making between patients and their providers related to lack of patient knowledge, inadequate communication, and mistrust.

Disclosure of Interest: C. Lemay Grant/research support from: Pfizer Inc, K. Mazor Grant/research support from: Pfizer Inc, J. Kremer Shareholder of: Corrona, Grant/research support from: Abbvie, Genentech, Lilly, Novartis, Pfizer, Employee of: Corrona, Speakers bureau: Genentech (non-promotional only, W. B. Nowell: None declared, C. Bingham III Consultant for: Bristol-Myers Squibb, J. Curtis Grant/research support from: Roche/Genentech, UCB, Janssen, Corrona, Amgen, Pfizer, BMS, Crescendo, AbbVie, Consultant for: Roche/Genentech, UCB, Janssen, Corrona, Amgen, Pfizer, BMS, Crescendo, AbbVie, E. Ruderman Grant/research support from: Pfizer Inc, Amgen, Consultant for: AbbVie, Amgen, Lilly, Novartis Pharmaceutical Corporation, Pfizer Inc., Janssen Pharmaceutica Product, L.P., L. Harrold Shareholder of: Corrona, Grant/research support from: Pfizer Inc, Consultant for: Roche Pharmaceuticals, Employee of: Corrona DOI: 10.1136/annrheumdis-2017-eular.3930

\section{SAT0751-HPR THE RELATIONSHIP BETWEEN ANAEROBIC EXERCISE CAPACITY AND ISOMETRIC LOWER EXTREMITY MUSCLE STRENGTH IN CHILDREN WITH JUVENILE IDIOPATHIC ARTHRITIS}

D. Bayraktar ${ }^{1}$, S. Savci ${ }^{2}$, E. Manci $^{3}$, O. Altug-Gucenmez ${ }^{4}$, B. Makay ${ }^{4}$, N. Illcin ${ }^{2}$ S.E. Unsal ${ }^{4}{ }^{1}$ Faculty of Health Sciences, Department of Physiotherapy and Rehabilitation, Izmir Katip Celebi University; ${ }^{2}$ School of Physical Therapy and Rehabilitation; ${ }^{3}$ Institute of Health Sciences; ${ }^{4}$ Faculty of Medicine, Division of Pediatric Rheumatology, Dokuz Eylul University, Izmir, Turkey

Background: Juvenile idiopathic arthritis (JIA) is a chronic disease that occurs before the age of 16 years. It was shown that anaerobic exercise capacity, which is important for most daily activities in children such as jumping, hoping and climbing was diminished in JIA. Previous studies showed that anaerobic exercise capacity was related to well-being level, functional status, and aerobic exercise capacity in JIA. However, no data is available about the relationship between lower extremity muscle power and anaerobic exercise capacity in children with JIA.

Objectives: To determine the possible relationships between lower extremity muscle strength and anaerobic capacity.

Methods: Forty-six children with JIA (14 F, $32 \mathrm{M}$ ), with a mean age of $13.74 \pm 2.29$ years (min-max: 9-17 years) were included in the study. Isometric lower extremity muscle strength was assessed with a hand-held dynamometer at the end points of knee flexion, knee extension, hip flexion and hip extension movements, which are generated from gross lower extremity muscles and important for anaerobic power. All the muscle testing was performed on the right leg. Anaerobic exercise capacity was measured performing a 30-second Wingate test. Both absolute and per kilogram values for peak power and average power were noted. The relationships between the parameters were determined with Pearson's correlation coefficient. (Relationship levels were interpreted as $0.05-0.30$ : low correlation; 0.30-0.40: low-moderate correlation; $0.40-0.60$ : moderate correlation; $0.60-0.75$ : good correlation; $0.75-1.00$ : good-excellent correlation.

Results: All children completed the assessments without any adverse effects. Demographics, average isometric lower extremity muscle strengths and param-

Table 1. Demographics, isometric lower extremity muscle strength and anaerobic exercise capacity parameters

\begin{tabular}{lc}
\hline & Mean \pm SD \\
\hline Age (years) & $13.74 \pm 2.29$ \\
Height $(\mathrm{cm})$ & $159.72 \pm 11.08$ \\
Weight $(\mathrm{kg})$ & $53.76 \pm 14.95$ \\
BMl $\left(\mathrm{kg} / \mathrm{m}^{2}\right)$ & $20.76 \pm 3.92$ \\
Hip Flexion $(\mathrm{kg})$ & $16.81 \pm 5.47$ \\
Hip Extension $(\mathrm{kg})$ & $13.57 \pm 4.50$ \\
Knee Flexion $(\mathrm{kg})$ & $17.72 \pm 5.83$ \\
Knee Extension $(\mathrm{kg})$ & $22.08 \pm 6.94$ \\
Peak Power $(\mathrm{W})$ & $386.26 \pm 184.08$ \\
Peak Power $(\mathrm{W} / \mathrm{kg})$ & $6.99 \pm 2.33$ \\
Average Power $(\mathrm{W})$ & $287.69 \pm 129.53$ \\
Average Power $(\mathrm{W} / \mathrm{kg})$ & $5.22 \pm 1.60$ \\
\hline SD: Standard Deviation; $\mathrm{cm}$ : centimeters; $\mathrm{kg}:$ kilogram; m: meter; W: watt; W/kg: watt/kilogram.
\end{tabular}

Table 2. The relationships between isometric muscle strength and anaerobic exercise capacity parameters

\begin{tabular}{lcccc}
\hline & $\begin{array}{c}\text { Peak Power } \\
(\mathrm{W})\end{array}$ & $\begin{array}{c}\text { Peak Power }) \\
(\mathrm{W} / \mathrm{kg})\end{array}$ & $\begin{array}{c}\text { Average Power } \\
(\mathrm{W})\end{array}$ & $\begin{array}{c}\text { Average Power } \\
(\mathrm{W} / \mathrm{kg})\end{array}$ \\
\hline Hip Flexion $(\mathrm{kg})$ & $0.688^{\star}$ & $0.629^{\star}$ & $0.636^{\star}$ & $0.552^{*}$ \\
Hip Extension $(\mathrm{kg})$ & $0.618^{\star}$ & $0.532^{\star}$ & $0.581^{*}$ & $0.458^{*}$ \\
Knee Flexion $(\mathrm{kg})$ & $0.642^{\star}$ & $0.530^{\star}$ & $0.630^{\star}$ & $0.494^{\star}$ \\
Knee Extension (kg) & $0.647^{\star}$ & $0.465^{\star}$ & $0.670^{\star}$ & $0.469^{\star}$ \\
\hline
\end{tabular}

Pearson Correlation Test; kg: kilogram; W: watt; W/kg: watt/kilogram. ${ }^{*}$ Significance at level $<0.001$.

eters related to the anaerobic exercise capacity testing were shown at Table

1. Moderate to good correlations were determined between isometric muscle strength and anaerobic exercise capacity parameters $p<0.001$ (Table 2).

Conclusions: The results of this study suggested that lower extremity muscle strength might influence the anaerobic exercise capacity. Exercise regimes including lower extremity strengthening might help improving anaerobic exercise capacity in children with JIA.

Disclosure of Interest: None declared

DOI: 10.1136/annrheumdis-2017-eular.5697

\section{SAT0752-HPR THE MEASUREMENT OF PATIENTS' EXPECTATIONS OF A MULTIDISCIPLINARY AND DEDICATED FIBROMYALGIA PROGRAM}

D. Xhaxho, A.A. Borg, C. Mercieca. Rheumatology, Mater Dei Hospital, Swatar, Malta

Background: Fibromyalgia (FM) is a chronic and multidimensional condition impacting the physical health and psychosocial state of the individuals. In addition to performing clinical and psychological assessments, evaluating patients' expectations may help address their specific needs and improve outcomes.

Objectives: The aim of this study was to assess the expectations of a cohort of FM patients participating in a multidisciplinary, dedicated fibromyalgia program. Methods: This was a survey of 86 consecutive FM patients who were initiating a multidisciplinary program delivered by a rheumatologist, nurse, physiotherapist, occupational therapist, psychotherapist and GP with a special interest in FM. Patients were diagnosed using the 2010 ACR diagnostic criteria. Demographic data, Widespread Pain Index (WPI), Symptom Severity Score (SSS) were recorded. Patients filled in the self-administered questionnaires including the Revised fibromyalgia impact questionnaire (FIQR), Hospital Anxiety and Depression Scale (HADS) and a patients' expectations questionnaire. The latter consisted of both open ended and closed questions using a five- point Likert scale ( $1=$ strongly agree to $5=$ strongly disagree) about the following domains; physical, psychological, coping and social aspects.

Results: Eighty six patients ( $92 \%$ females) participated in the survey. The average age was 51.2 years (SD 10.60) and mean duration of symptoms 13.3 years (SD 11.17). The mean HADS-A was 11.6 (SD 4.37), HADS-D 8.67 (SD 3.47) and FIQR 55.9 (SD 21.64). In response to an open question about what was their main expectation from this program, just over half of the patients $(52.3 \%)$ reported improvement of pain and fatigue as their most important outcome. This was followed by improved quality of life (19.3\%), being able to cope better with ADLs, family and work (17.4\%), obtain more knowledge about the condition $(5.8 \%)$, while $15.1 \%$ did not have any expectations. When asked to rate their expectations for each specific domain: $64 \%$ expected significant improvement of physical symptoms, $74 \%$ to be able to cope better with family, hobbies and work and $66 \%$ expected an improvement of their psychological state, namely depression and anxiety. By the end of the program, $66 \%$ of the patients expected to have minimal or no symptoms. When asked to identify any lifestyle changes which could help, $30.2 \%$ mentioned a better work-life balance, $12.8 \%$ starting an exercise routine, $10.5 \%$ weight loss, $11.6 \%$ a mixture of house adaptations while $34.9 \%$ could not come up with any suggestions.

Conclusions: Expectations of fibromyalgia patients were high in all domains. This study highlights the need for multidimensional assessment and a personalised treatment approach in managing fibromyalgia. Moreover, it is very important to assess patients' expectations in order to guide interventions and set realistic achievable goals which are acceptable to both patients and clinicians. Patients' expectations are an important patient reported outcome measure, which need to be assessed.

\section{References:}

[1] Goffaux P, De Souza J, Potvin S, Marchand S(2009) Research papers: Pain relief through expectation supersedes descending inhibitory deficits in fibromyalgia patients. Pain 145:18-23.

[2] Hamnes B, Hauge M, Kjeken I, Hagen K (2011)' I have come here to learn how to cope with my illness, not to be cured': A Qualitative Study of Patient Expectations Prior to a One-Week Self-Management Programme. Musculoskeletal Care 9(4):200-210.

Disclosure of Interest: None declared

DOI: 10.1136/annrheumdis-2017-eular.1599 